\title{
Evaluation of Welding Properties of Metallic Foil with an Electron Beam*
}

\author{
Ming YANG**, Hiroki OGAWA** and Shoji FUJIOKA** \\ ** Graduate school of System design, Tokyo Metropolitan University, \\ 6-6 Asahigaoka, Hino-shi, Tokyo, Japan \\ E-mail: yang@tmu.ac.jp
}

\begin{abstract}
For the fabrication of MEMS or devices in micro scale, joining of small parts is a critical issue. In this study, thin metal foils were welded using electron beam welding to investigate the weldability of the foils. In the welding of thin foils, the heat-affected zone and welding state are strongly dependent on the energy density of the irradiation beam, and size effects, such as heat capacity and stiffness, are important as the thickness of the material becomes small. Two materials, stainless steel and titanium with thickness values of $10 \mu \mathrm{m}$ and $20 \mu \mathrm{m}$, were used as workpieces. An electron beam with several incident energies was applied, and the surfaces and cross-sections of the weld zones of the workpieces were examined. The experimental results show that the weldability of foil welding strongly depends on the material properties and the thickness of the workpieces, and it becomes more difficult to weld two overlapping foils with smaller thickness and lower thermal conductivity.
\end{abstract}

Key words: Electron Beam Welding, Thin Metal Foil, Size Effect, Heat-Affected Zone, Thermal Conductivity

\section{Introduction}

The fabrication of micro electro mechanical systems (MEMS) and other micro scale devices using metallic materials has attracted significant attention over the last decade. Metallic materials have high strength, ductility, and conductivity. Furthermore, metallic materials can be mass produced by metal forming. Micro-metal forming techniques for the production of small parts have been previously investigated, including micro-piercing, micro-drawing, and micro-forging. For the fabrication of micro-devices, the joining of small parts is as important as forming. However, it is difficult to join parts with micron size due to its low stiffness and heat capacity, and unfortunately, there has little research in this area.

Several previous studies have been conducted on high energy beam welding as a bonding method for micron-sized parts such as thin metallic foils ${ }^{(1)-(4)}$. As another welding process, Takagi et al. ${ }^{(5)}$ investigated surface activated bonding because MEMS devices were supposed to suffer from large heat damage. Electron beam welding of metallic foils was investigated by the present authors ${ }^{(6)}$ due to its advantages of deep penetration and thin widths. Electron beam welding was also used in the fabrication of a micro-pump to improve the seal between the chassis plate and the lamina. However, in the case of circumferential welding, the lamina was not welded and melting deformation occurred away from the chassis plate. In the case of spot irradiation, the lamina melted and opened a hole, and thus was not welded to the chassis plate. Both experiments verified that the diffusion of heat is large because the chassis plate is thick compared to the lamina. 
Electron beam welding is thus useful for bonding micron-sized components, however, the difficulty of handling parts remains a problem. As the thickness of the material becomes thinner and heat damage becomes larger, it is easy for the material to melt and form defects such as holes. In the case of welding of thin metallic foils, a slight gap between the overlapping foils forms easily during handling, and welding due to the small stiffness of the foils. V. Frank et al. ${ }^{(7)}$ have discussed the size effect during foil welding. Additionally, Misu et al. ${ }^{(8)}$ investigated the deformation mechanism of laser bending.

In this study, thin metal foils were welded by electron beam welding to investigate the characteristics in detail for different incident energies of the electron beam. Furthermore, the effects of material properties and size effects such as stiffness on the weldability of metal foils were investigated.

\section{Experiments}

Figure 1 shows a schematic of the electron beam welder equipment and the path of the electron beam. The design of this device is based on the SEM, and the principle of generation of the electron beam is the same as in the SEM. As shown in Fig. 1, thermal electrons are generated from the thermal electron gun. The electrons are accelerated by a high voltage, focused by the condenser lens, and changed to heat energy from kinetic energy. The specimen in the vacuum chamber is heated by the impinging electrons. The power of the electron gun was raised when welding the thin foils, but was reduced for observations. The specification of the experimental equipment is shown in Table 1 . The

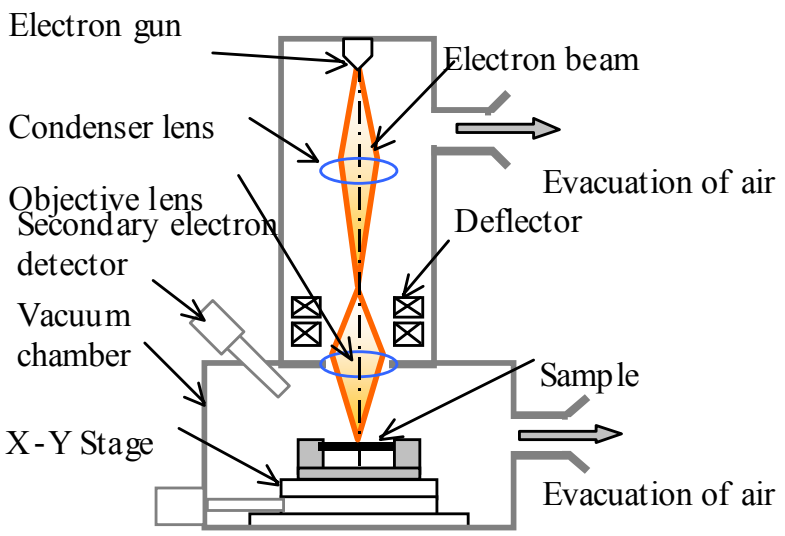

Fig. 1 Sche matic of electron beam welder

Table 1 - Specification of experimental equipment

\begin{tabular}{c|c}
\hline \multicolumn{2}{c}{ Electron beam system } \\
\hline Work region $[\mathrm{mm}]$ & $60 \times 75 \times 10$ \\
Maximum acceleration voltage $[\mathrm{kV}]$ & 30 \\
Current of beam $[\mu \mathrm{A}]$ & $0.1-150$ \\
Working distance $[\mathrm{mm}]$ & 60 \\
\hline \multicolumn{2}{c}{ Sample stage } \\
Minimum driving $[\mu \mathrm{m}]$ \\
Driving method & 0.1 \\
\hline Vacuum evacuation system & AC servo drive \\
\hline Vacuum degree of electron gun $[\mathrm{Pa}]$ & $2.5 \times 10^{-5}$ \\
Vacuum degree of sample chamber $[\mathrm{Pa}]$ & $1 \times 10^{-3}$ \\
\hline
\end{tabular}


equipment consists of an electron beam system, a sample stage and a vacuum evacuation system. The maximum acceleration voltage is $30 \mathrm{kV}$ and the range of the beam current is $0.1 \mu \mathrm{A}$ to $150 \mu \mathrm{A}$. The intensity of the electron beam depends on the focal length and beam diameter. The focal length and beam diameter of the beam were adjusted to reach maximum intensity. The beam current and beam diameter were measured and adjusted before each experiment. The beam diameter was fixed to $12 \mu \mathrm{m}$, and the maximum change in the diameter was about $3 \mu \mathrm{m}$ due to variation of the beam current.

Table 2 - Material properties

\begin{tabular}{c|c|c}
\hline Materials & SUS304 & $\mathrm{Ti}$ \\
\hline Melting point $[\mathrm{K}]$ & $1673-1700$ & 1941 \\
\hline Heat conductivity $[\mathrm{W} /(\mathrm{m} \mathrm{K})]$ & 17.21 & 21.9 \\
\hline Heat expansion coefficient $[1 / \mathrm{K}]$ & 17.3 & 8.4 \\
\hline
\end{tabular}

Two materials, stainless steel (SUS304) and titanium (Ti), were used as workpieces since the purpose of this study is attempt to fabricate micro components for medical application, and most of metallic components in medical equipment is made of stainless steel or Titanium. The material properties of the workpieces are shown in Table 2 . The melting point of SUS304 and the heat conductivity of SUS304 are lower compared to Ti, and these properties affect the experimental results. In the macroscale, the welding of SUS304 is easier than Ti due to the lower heat conductivity of the former. However, in the microscale, this tendency could be changed due to the size effect. The conditions for spot irradiation and overlap welding are shown in Table 3. Both ends of a specimen were attached in a fixture, which is designed to improve the contact between overlapping foils and to add tensile force to the workpiece. Two thicknesses of the specimens of $20 \mu \mathrm{m}$ and $10 \mu \mathrm{m}$ were used. The electron beam irradiation time of the foils ranged from 1 to 15 seconds, and the scanning speeds used were $6 \mu \mathrm{m} / \mathrm{sec}, 33 \mu \mathrm{m} / \mathrm{sec}$ and $61 \mu \mathrm{m} / \mathrm{sec}$ for overlap welding. The accelerating voltage was maintained constant, while the beam current was changed.

Table 3 - Experimental conditions

\begin{tabular}{c|c}
\hline Materials & Titanium, SUS304 \\
\hline Thickness $\mathrm{T}[\mu \mathrm{m}]$ & 20,10 \\
\hline Irradiation time IT $[\mathrm{sec}]$ & $1,3,5,10,15$ \\
\hline Scanning speed SP $[\mu \mathrm{m} / \mathrm{sec}]$ & $6,33,61$ \\
\hline Beam current BC $[\mu \mathrm{A}]$ & $10-50$ \\
\hline Accelerating voltage AV $[\mathrm{kV}]$ & 30 \\
\hline
\end{tabular}

The effects of incident heat quantity and scanning speed on the heat affected zone, surface state and weldability were investigated. Two kinds of experiments were carried out. First, a thin single foil was irradiated with the electron beam. After the irradiation, the melted zone was observed using an SEM and a confocal laser scanning microscope (CLSM) to measure its shape, dimensions and surface state. A schematic of spot irradiation on a thin film is shown in Fig. 2(a). The relationship between the incident energy and diameter of the heat affected zone was investigated. Suitable condition for the irradiation also investigated.

Next, the electron beam was scanned onto specimens of two overlapping thin foils. Four combinations were used: two Ti foils were overlapped (Ti/Ti), two SUS304 foils were overlapped (SUS304/SUS304), Ti was on top and SUS304 on the bottom (Ti/SUS304) and 
SUS304 was on top and Ti on the bottom (SUS304/Ti). A schematic of the overlapped welding of the thin foils is shown in Fig. 2(b). After welding, both the top and bottom of the welded zone were observed in the SEM. Cross-sections of the weld zone were then observed using CLSM for confirming the welding state. Incident power of the electron beam was changed by the current value. The energy density of then beam can be defined as the incident power divided by area of the incident beam. Current value was detected with a Faraday cup before each experiment. The heat quantity for spot irradiation $\left(\mathrm{Q}_{\mathrm{S}}[\mathrm{J}]\right)$ is defined as the product of the incident power and irradiation time, and the heat quantity per unit length for line scanning $\left(\mathrm{Q}_{\mathrm{L}}[\mathrm{J} / \mathrm{mm}]\right)$ is defined as the incident power divided by the scanning speed.

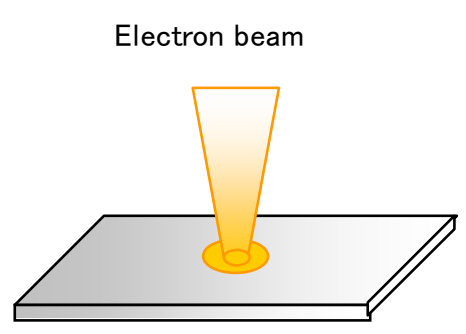

(a) Spot irradiation

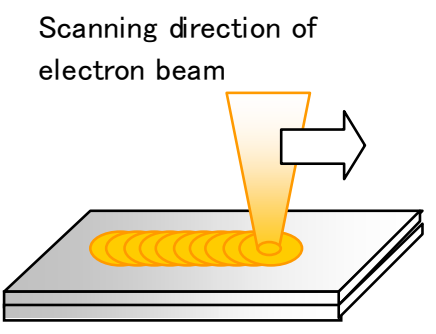

(b) Scanning Welding

Fig. 2 Schematics of electron beam welding of thin films: (a) Spot irradiation of a thin film, (b) Line scanning of thin films

\section{Results and discussions}

\subsection{Effect of Input Heat Quantity on Heat Affected Zone and Weldability}

Figure 3 shows the material characteristics after the irradiation. SUS304 with thickness of $20 \mu \mathrm{m}$ was used as the workpiece. The workpiece can be classified into three regions, the molten zone, heat-affected zone and base material. Figure 3 (a) shows the resultant characteristics after spot irradiation, and Fig. 3 (b) shows the material characteristics after the line scanning. The structure of weld metal varied due to crystallization in the molten zone. It is easy to find the molten zone and the heat-affected zone from the observation

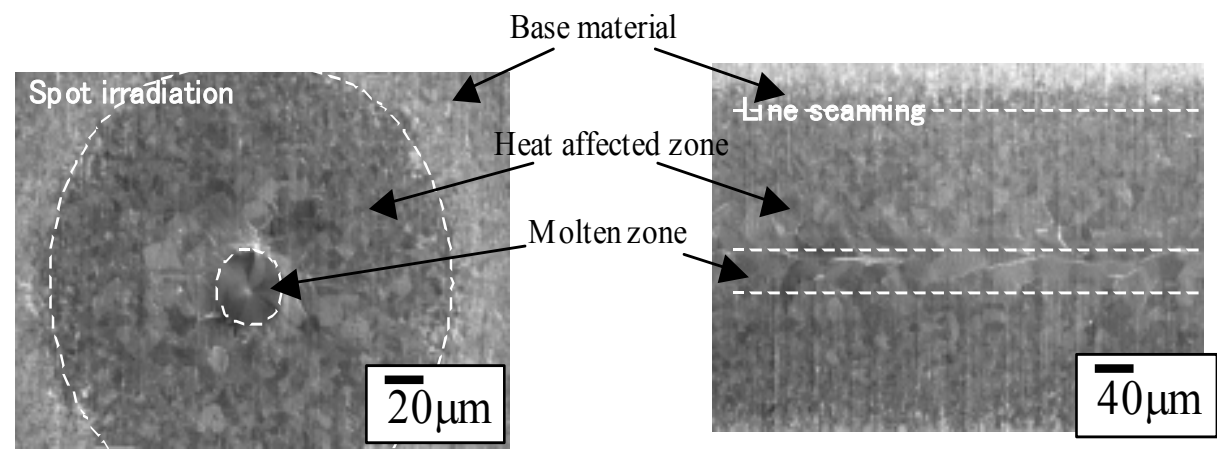

(a) Material characteristics on spot irradiation

(b) Material characteristics on line scanning

Fig. 3 Image of heat affected zone after EB irradiation with conditions of (a) IT=5s, BC=14.2 $\mu \mathrm{A}$, (b) $\mathrm{SP}=33 \mu \mathrm{m} / \mathrm{s}, \mathrm{BC}=21.7 \mu \mathrm{A}$. 


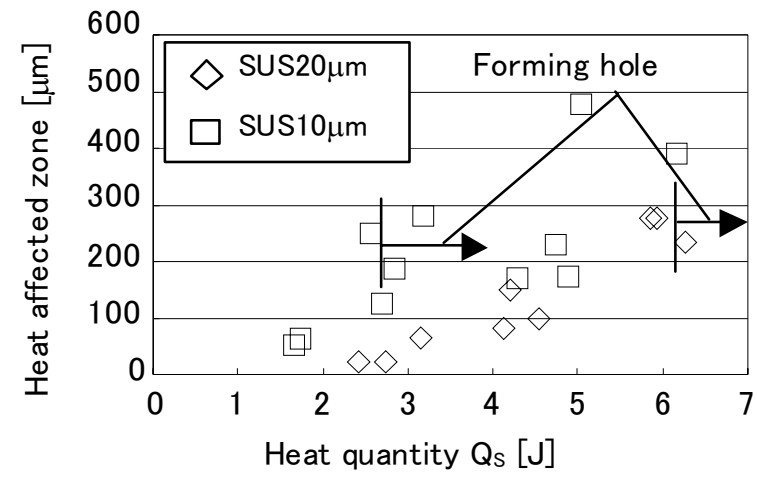

(a) SUS304 foil

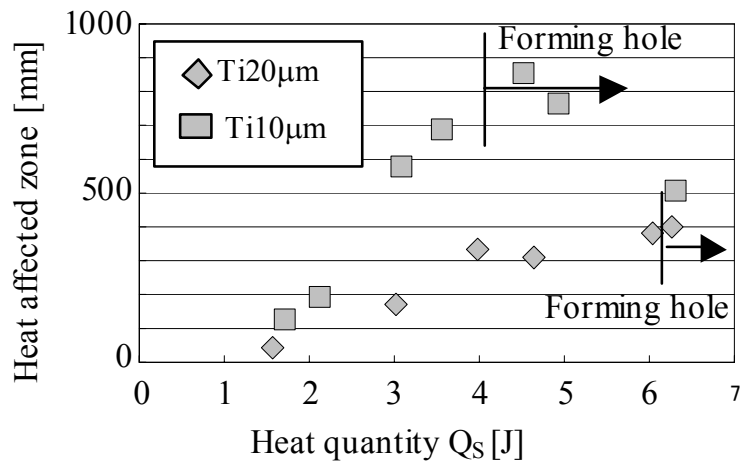

(b) Ti foil

Fig. 4 Effect of input energy to HAZ in s pot irradiation (Irradiation time : 5s)

image. The dimensions of the heat-affected zone were several times larger than those of the molten zone, as show in Figs. 3 (a) and (b).

The effects of the incident heat quantity on the heat-affected zone after electron beam irradiation were investigated. The irradiation time was fixed at 5 seconds. Figure 4 shows the relationship between the incident heat quantity and the heat-affected zone in the SUS304 and Ti foils. As the heat quantity increased, the diameter of the heat-affected zone also increased. It is easy to form a hole since the incident energy becomes larger for materials with lower heat conductivity and thinner foils. Figure 5 shows the effect of the input heat quantity on the heat-affected zone for the line scanning. The scanning speed of the electron beam was fixed at $33 \mu \mathrm{m} / \mathrm{s}$, and heat quantities per unit length were of 20 $\mathrm{J} / \mathrm{mm}, 30 \mathrm{~J} / \mathrm{mm}, 40 \mathrm{~J} / \mathrm{mm}$, respectively. With increasing heat quantity, the heat-affected

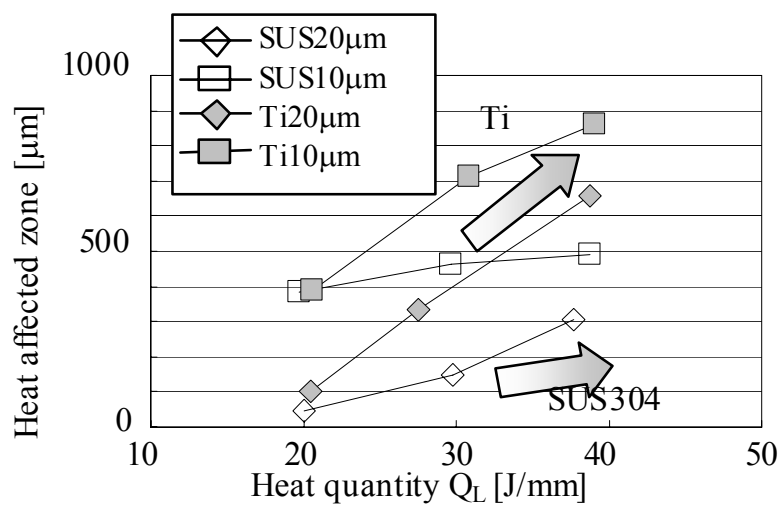

Fig. 5 Effect of input energy to HAZ in line scanning (Scan ning speed : $33 \mu \mathrm{m} / \mathrm{s}$ ) 
zone became larger while workpiece became thinner. The dimension of the heat-affected zone was several tens to hundreds of $\mu \mathrm{m}$, and the heat affected zone of the Ti foil was larger than that of the SUS304 foil for both spot irradiation and line scanning. As the thickness of foil decreased, dimension of the heat-affected zone became larger.

Figure 6 shows the relationship between the energy density of the incident beam and the welding state of $20 \mu \mathrm{m}$ and $10 \mu \mathrm{m}$ thick foils. Figures 6 (a) and (b) show the results for spot irradiation and line scanning, respectively. The irradiation time for the spot irradiation and scanning speed for line scanning were fixed constantly. The weldability ranged between two solid lines. It is seen that weldability strongly depends on the energy density. For the welding of two overlapped foils, the top side foil needs to be sufficiently molten to the back side, and the surface state can be classified into three categories same as mentioned in previous work ${ }^{(6)}$. This indicates that the foil forms a hole if the energy density increases significantly. The range of the molten materials through to the backside is narrower with decreasing heat conductivity of the material. A lower energy density is needed to melt the backside for thinner material, though the range of forming a hole becomes wider. A smaller thickness results in lower heat capacity, and consequently, lower heat conductivity causes a concentration of heat at the center of the foil. The excess quantity of the heat remains in the foil, and contributes to generation of a defect such as a hole. The feasible region for overlap welding can be estimated from these results as a function of the incident heat quantity, material properties and thickness.

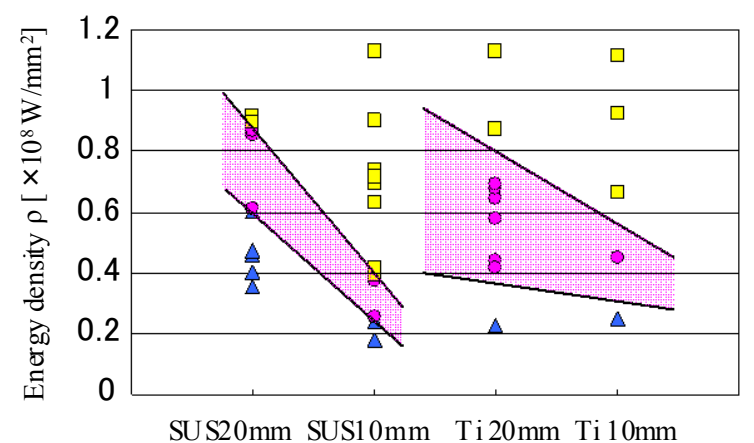

(a) Spot irradiation (Irradiation time $=5 \mathrm{~s}$ )

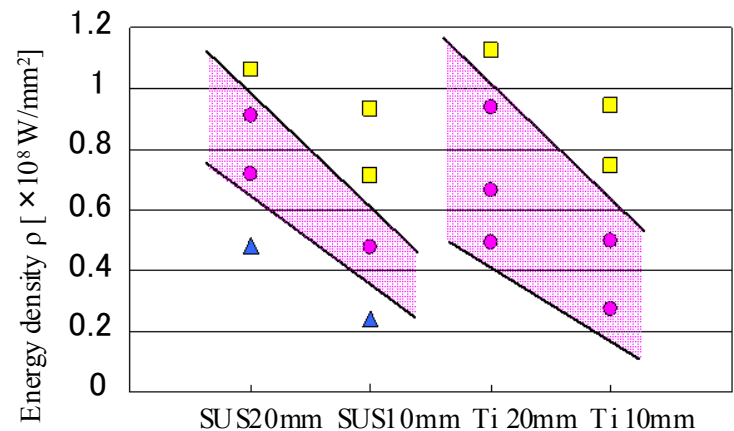

(b) Line scanning (Scanning speed $=33 \mu \mathrm{m} / \mathrm{s}$ )

$$
\begin{aligned}
& \Delta \text { Surface melting } \\
& \bigcirc \text { Through to the other side } \\
& \square \text { Forming hole }
\end{aligned}
$$

Fig. 6 Relationship between energy density and weldability 


\subsection{Effect of Material Stiffness}

Thermal deformation due to electron beam irradiation and lower bending stiffness also affect the weldability of the foils. The bending stiffness of a thin foil can be expressed as:

$$
E I=\frac{E \cdot W \cdot h^{3}}{12}
$$

where $E$ is the Young's modulus, I is the second moment of the area of a rectangle, $W$ is width, and $h$ is the thickness.

As the thickness of the material become smaller, the bending stiffness decreases significantly due to the size effect. The foils are easily distorted during heating or handling, and eventually a gap forms between the overlapped foils. Figure 7 shows the thermal deformation after the electron beam was scanned on a single foil with thickness of $20 \mu \mathrm{m}$. Figure 7 (a) shows a schematic of thermal deformation and the deformation angle, Fig. 7 (b) shows the surface profile of SUS304, and Fig. 7 (c) shows the surface profile of Ti near the center of molten zone, respectively. The deformation of the SUS304 and Ti foils was measured to be in the range of $500 \mu \mathrm{m}$ from the center of the molten zone. The average deformation of the SUS304 was $33 \mu \mathrm{m}$ and that of Ti was $23 \mu \mathrm{m}$. Figure 8 shows the measured thermal deformation angle for SUS304 and Ti. It is seen that the resultant deformation angle for SUS304 is larger than that for Ti. This means that a gap could exist when the foils overlap, and in addition could increase due to heat distortion after electron beam irradiation. Since heat expansion of SUS304 is two times larger than that of Ti, the distortion of SUS304 was larger and as a result, the weldability is reduced.

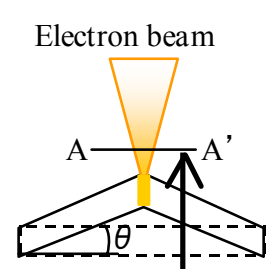

Deformation of foil

$\theta$ : Deformation angle

(a) Schematic of foil deformation
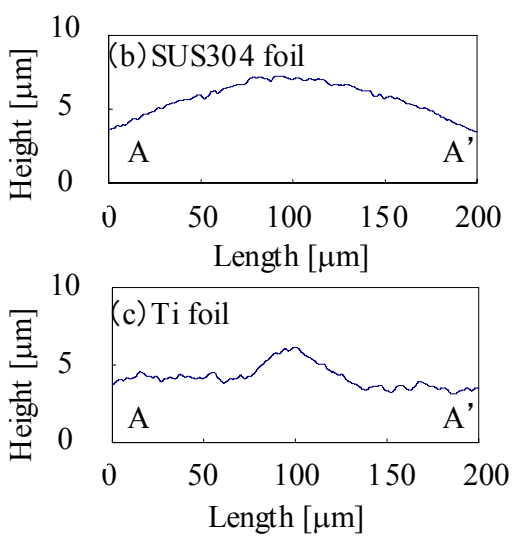

Fig. 7 Deformation after irradiated electron be am wi th conditions of (b) $Q \mathrm{~L}=37.7 \mathrm{~J} / \mathrm{m}$, and (c) $Q \mathrm{~L}=38.8 \mathrm{~J} / \mathrm{mm}$

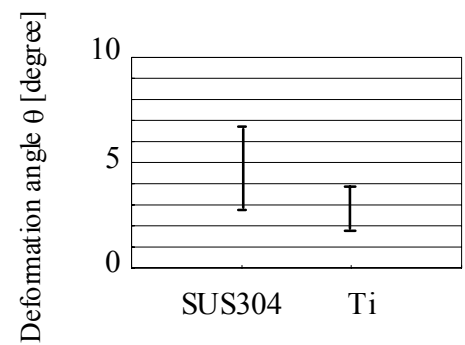

Fig. 8 Defor mation angle of S US304 and Ti

\subsection{Welding of Similar and Dissimilar Materials}

The overlapped foils with a total thickness of $40 \mu \mathrm{m}$ were irradiated with the electron 
beam and the weldability was investigated with different combinations of SUS304 and Ti, as mentioned earlier. Figure 9 shows cross-sectional images of the welded zone measured with the CLSM. The bead widths in average were calculated from SEM observations of the surface and cross-sectional images of CLSM. Table 4 shows the average bead widths. The bead widths for SUS304 and Ti were different due to the different material properties such as heat conductivity. The welded width for SUS304/SUS304 was the shortest and the welded width for $\mathrm{Ti} / \mathrm{Ti}$ was the longest. Welded width of the cross-section of SUS304/SUS304 was same compared to that of the top side though there was no welded

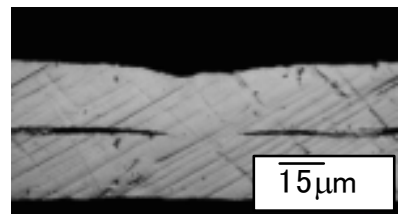

(a) SUS/SUS

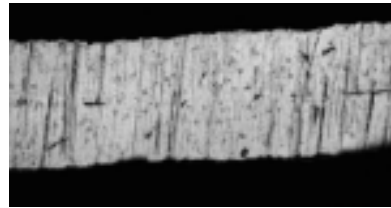

(c) $\mathrm{Ti} / \mathrm{Ti}$

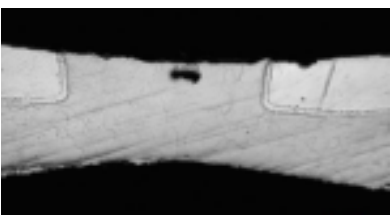

(b) SUS/Ti

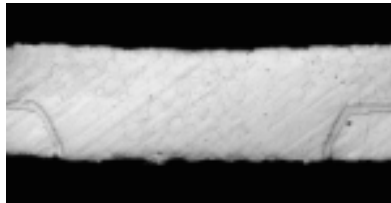

(d) Ti/SUS

Fig. 9 Cross section of overlapped foils welded by conditions of (a) $\mathrm{SP}=33 \mu \mathrm{m} / \mathrm{s}, Q \mathrm{~L}=45 \mathrm{~J} / \mathrm{mm}$, (b) $\mathrm{SP}=33 \mu \mathrm{m} / \mathrm{s}, Q \mathrm{~L}=45 \mathrm{~J} / \mathrm{mm}$, (c) $\mathrm{SP}=33 \mu \mathrm{m} / \mathrm{s}, Q \mathrm{~L}=45 \mathrm{~J} / \mathrm{mm}$, (d) $\mathrm{SP}=61 \mu \mathrm{m} / \mathrm{s}, Q \mathrm{~L}=25 \mathrm{~J} / \mathrm{mm}$.

Table 4 Weld width of overlapped welding

\begin{tabular}{|c|c|c|c|c|}
\hline & \multicolumn{2}{|c|}{ Width of Surface $[\mu \mathrm{m}]$} & \multirow{2}{*}{\multicolumn{2}{|c|}{$\begin{array}{l}\text { Width of cross } \\
\text { section }[\mu \mathrm{m}]\end{array}$}} \\
\hline & Top side & Back side & & \\
\hline SUS/SUS & 27 & None & \multicolumn{2}{|c|}{24} \\
\hline SUS/Ti & 59 & 121 & 66 & 126 \\
\hline Ti/SUS & 196 & 93 & 180 & 90 \\
\hline $\mathrm{Ti} / \mathrm{Ti}$ & 301 & 247 & \multicolumn{2}{|c|}{264} \\
\hline
\end{tabular}

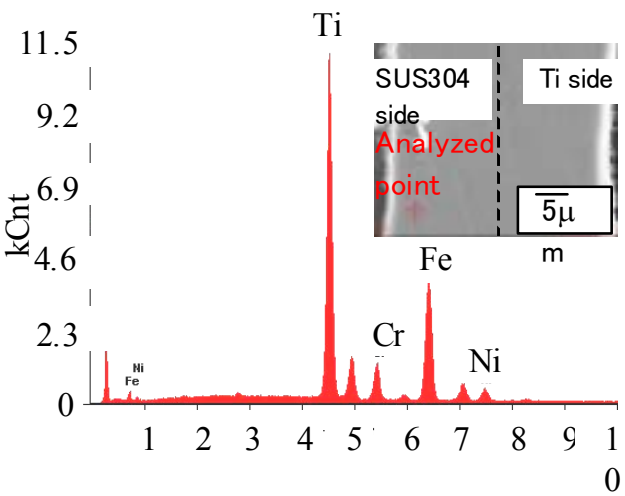

Energy $[\mathrm{keV}]$

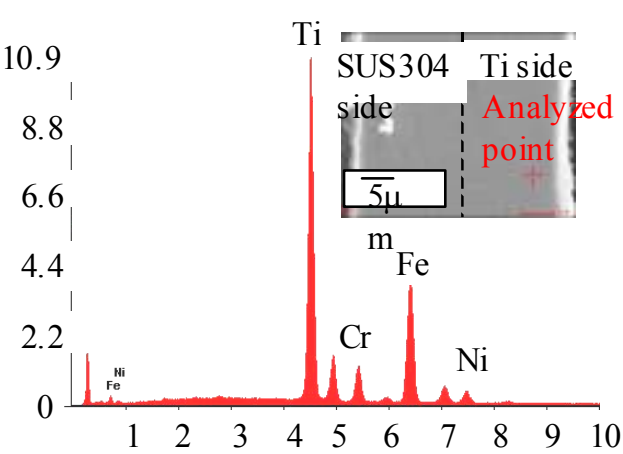

Energy $[\mathrm{keV}]$

Fig. 10 Chemical composition analysis of weldedzone using EDX 
zone to back side. However the cross-section of $\mathrm{Ti} / \mathrm{Ti}$ was intermittent and welded width of the cross-section was narrower than that of the top side. Welded width becomes narrow as close to back side from top side. For the combinations of SUS304/Ti and Ti/SUS304, the welded width of $\mathrm{Ti}$ was longer compared to SUS304. Figure 10 shows chemical composition analysis for cross-sections of the welded zone using EDX. Peaks of Fe, $\mathrm{Cr}$, $\mathrm{Ni}$ and Ti could be confirmed for each cross-section. The results show that the chemical compositions of SUS304 and Ti have molten each other at welded zone.

Figure 11 shows the weldability of the overlapped welding with the different material combinations with the thickness of $20 \mu \mathrm{m}$. Each plot in the figure indicates whether the welding was successful to obtain a continuous bead. The results show that the SUS304/Ti and Ti/Ti combinations have better weldability in the ranges of the scan speed and the heat quantity compared to others. In the case of similar materials, weldability was higher for the material with the higher heat conductivity. On the other hand, in the case of dissimilar materials, weldability became higher with the combination of a material with a lower heat conductivity on the topside and a material with a higher heat conductivity material on the backside. Furthermore, as the thickness of the material is reduced, welding of overlapped foils is difficult since a gap may exist between the foils due to the size effect caused by differences in heat capacity and low stiffness. As a result, the weldability of a material with low heat conductivity and high heat expansion will be reduced due to larger deformation during electron beam irradiation.
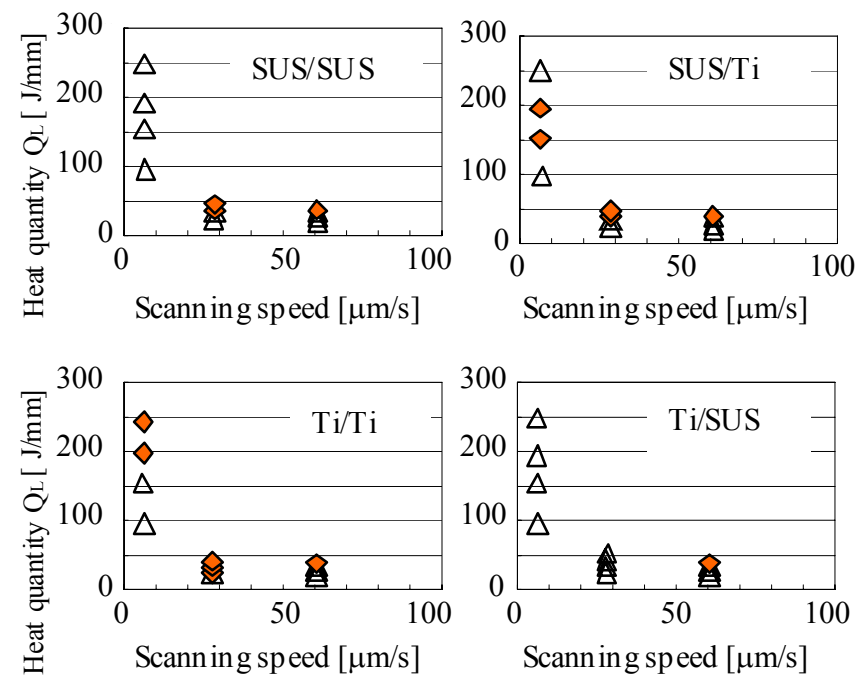

$$
\begin{array}{ll}
\triangle & \text { Continuous bead } \\
\Delta & \text { Failure }
\end{array}
$$

\section{Fig. 11 Wel dability of overlapped welding}

\subsection{Application for Welding a Thin-Walled Tube}

Overlapped welding was carried out for a cylindrical-shaped material, which was Ti foil with a thickness of $20 \mu \mathrm{m}$. The Ti foil was bent to a cylindrical-shape by a bending tool and held with a fixture for the welding. The process conditions for the welding are of $\mathrm{BC}=32.3 \mu \mathrm{A}, \mathrm{SP}=33 \mu \mathrm{m} / \mathrm{s}$. Figure 12 shows the image of the welded tube of the Ti foil. The diameter of the tube is about $2 \mathrm{~mm}$. This indicates that electron beam welding is effective for the fabrication of three-dimensional structures. 


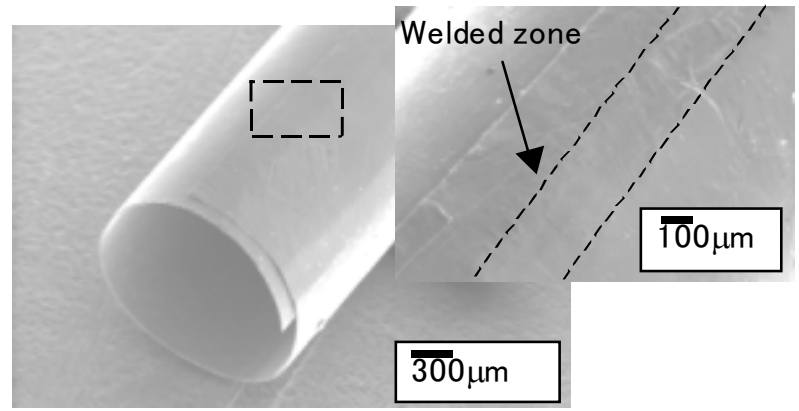

Fig. 12 Cylindrical welding of Ti foil

\section{Conclusions}

In this research, electron beam welding of foils was carried out. The effect of the input conditions of the electron beam, the material properties and the thickness on the heat-affected zone and weldability were investigated. The following conclusions were obtained.

-The incident heat quantity affects the dimensions of the heat-affected zone.

-The weldability of a material with higher heat conductivity and lower heat expansion material becomes higher in the micro-scale.

-The welding of foils is more difficult with decreasing thickness of the material. The decrease in the gap between foils also becomes more important for the welding of thin foils.

\section{Acknowledgments}

The authors will thank JAPAN Ministry of Economy, Trade and Industry for funding this work. The authors will also thank Mr. Sugiyama and Mr. Kojima for supporting the equipment operation and Dr. T. Furushima for supporting observation of the cross section.

\section{References}

(1) D. Jan, V. Ivan, Z. Martin, Electron gun for computer-controlled welding of small components, Vacuum 62, (2011), pp.59-164.

(2) N. Abe, M. Tsukamoto, T. Imaoka, J. Morimoto, Y. Funada, Influence of beam shape on lap welding of thin foils, Pre-prints of national meeting of JWS, vol. 77, (2005), pp. 246-247.

(3) K. Uota, T. Hishino, Fusion welding of thin metal plate and foil, Welding technology, 2007-4.

(4) U. Dilthey, T. Dorfmüller, Micro electron beam welding, Microsystem Technologies, vol.

12, (2006), pp 626-631.

(5) H. Takagi, R. Maeda, T. Suga, Wafer-scale spontaneous bonding of silicon wafers by argon-beam surface activation at room temperature, Sensors and Actuators A: Physical, vol. 105, (2003), pp. 98-102.

(6) H. Ogawa, M. Yang et al, Welding of metallic foil with electron beam, Journal of solid mechanics and materials, vol. 3, No. 4, (2009), pp. 647-655.

(7) V. Frank, W. Florian, T. Claus, Micro welding for environmental-friendly products, ICALEO Proceedings, (2007), pp. 143-148.

(8) T. Misu, Y. Sano, T. Miyazaki, S. Tanaka, Laser bending of thin metal plate, Japan Society for Precision Engineering, vol. 71, No. 12, (2005), pp. 1536-1540. 